\title{
Effect of COVID-19 pandemic on Education System in India
}

\author{
Dr. Divya Kashyap \\ Assistant Professor, Indian Academy Degree College Autonomous, Bangalore, India. \\ divya_compscience@indianacademy.edu.in
}

\begin{abstract}
The Covid-19 also known as Coronavirus is declared as pandemic in 2020 by almost all the countries around the globe. Pandemic like covid, H1N1 etc, is an event that will be remembered for a long time. The consequences of decisions taken by the government during pandemic will no doubt have a significant impact on the future development of global society. Education is one of the most important and affected area due to lockdown enforced due to pandemic. This paper tries to cover affect of covid pandemic on education system and economic of the India.
\end{abstract}

Keywords: Covid, H1N1, pandemic, disease, etc.

\section{INTRODUCTION}

Epidemics like H1N1, Corona etc, of infectious diseases are occurring more often, and spreading faster, in almost all regions of the world including India. The background factors of these epidemics are biological, environmental and lifestyle changes, among others. A potentially fatal combination of newly-discovered diseases, and the reemergence of many long-established ones, demands urgent responses in all countries in many areas like Industries, education etc. Planning and preparation to handle such epidemic, prevention and control are essential and most important.

For Social and economic development of any country, education is major factor and vehicle. All the governments are working for the expansion and development of their education system, to provide the economic benefit to the whole society. As a result of interruption in education due of epidemic will have a negative and permanent impact on communities and countries?

Ministries of education in different countries are not able to develop any strategies against to the epidemic like Corona, to handle the situation in educational institutes, due to the lake of adequate knowledge base.

Worldwide educational systems are affected due to the 2019-2020 corona viruses pandemic. Due to human to human spread, authorizes decided to close schools and universities. According to UNESCO monitoring, over 100 countries have implemented nationwide closures, impacting over half of the world's student population.

Educational institutes closures affect not only students, teachers and families, but have negative affect on various social and economic issues, digital learning, homelessness, students debts, food insecurity, housing, health care etc and ultimately economy of the country.

\section{Background of the Corona virus disease}

Corona virus disease 2019 (COVID-19) is an infectious disease caused by severe acute respiratory syndrome corona virus 2 (SARS-CoV-2).[2]The disease was first identified in 2019 in Wuhan, the capital of China's Hubei province, and has since spread globally, resulting in the 2019-2020 corona virus pandemic.[3][4] Common symptoms include fever, cough, and shortness of breath. Other symptoms may include muscle pain, sputum production, diarrhea, sore throat, and abdominal pain.[6],[5] While the majority of cases result in mild symptoms, some progress to pneumonia and multi-organ failure.[3],[7] As of March 25 , 2020, the overall rate of deaths per number of diagnosed cases is 4.5 percent; ranging from 0.2 percent to 15 percent according to age group and other health problems.

\section{PANDEMIC EFFECT ON EDUCATION IN} PAST

Corona is not the first pandemic affecting the education system. In past, outbreaks of various diseases(spread through virus) have disturbed the education in colleges and school around the world, with varying levels of effectiveness[8],[9],[10]. While trying to model mathematical, got that transmission of the virus may be delayed by closing the various institutes. Whereas, its effectiveness also depends on the contacts children and their families maintain outside of institute. If the decision of closures of an institute closures took place late relative to an outbreak, closure will be less effective and may not have any impact at all[8],[9]. Sometimes, in some cases, when the institute reopens after a period of closure, resulted in a small increase or slight upward trend in spread rates [11]. To control the affect of pandemic, closures doesn't imply only closure of educational institute but also, tend to 
occur concurrently with other interventions such as public gathering bans, it can be difficult to measure the specific impact of school closures.[11]

In the United States, During the 1918-1919 influenza pandemic, educational institute closures and public gathering like malls, parties etc bans were associated with lower total mortality rates[9]. Cities that decided and implemented such interventions such as closure of institutes at early stages earlier had greater delays in reaching peak mortality rates[12],[11]. Schools closed for a median duration of 4 weeks according to a study of 43 US cities' response to the Spanish Flu[12]. School closures were shown to reduce morbidity from the Asian flu by $90 \%$ during the 1957-58 outbreak,[13] and up to $50 \%$ in controlling influenza in the US, 2004-2008.[14]

During H1N1 Flu pandemic in 2009, multiple countries successfully slowed the spread of infection through school closures. Institute closures in the Oita, Japan and many other cities, were found to have successfully control the number of infected students when the infection was at its peak; however closing institutes was not found to have significantly decreased the total number of infected students[15]. Compulsory and strict closure of institutes and other social distancing measures were associated with a $29 \%$ to $37 \%$ reduction in influenza transmission rates. Despite the overall success of closing schools, a study of school closures in Michigan found that "district level reactive school closures were ineffective."[16]

In the UK , during the swine flu outbreak in 2009 , in an article published in the Lancet Infectious Diseases, titled "Closure of schools during an influenza pandemic", a group of epidemiologists certified that the closure of institutes in order to bread the chain of spread of the infection, slow further spread and buy time to research and produce a vaccine.[17] Previous studies on influenza pandemics including the 1918 flu pandemic, the influenza pandemic of 1957 and the 1968 flu pandemic, reported on the economic and workforce effect school closure would have, particularly with a large percentage of medical staff of whom half had children under the age of 16 . They also focused on the dynamics of the spread of influenza in France during French school holidays and spoke that cases of flu decreased when schools closed and re-occurred when they re-opened. They noted that In Israel in 1999-2000, when teachers went on strike during the flu season, visits to doctors and the number of respiratory infections dropped by more than a fifth and more than two fifths respectively.[18]

\section{TIMELINES DURING PANDEMIC COVID-}

\section{9}

Most education system around the world has temporarily decided to close educational institutions in order to control the spread of the COVID-19 pandemic. These decision and implementation of closures are impacting over $89 \%$ of the world's student population studying in school and colleges. Several other countries including India, have implemented localized closures of malls and coaching to avoid gathering, impacting millions of additional learners. Next, various dates when different countries decided to implement the lockdown of educational institute to avoid the spread.

- $\quad$ On 31 December 2019, a pneumonia of unknown cause detected in Wuhan, China was first reported to the WHO Country Office in China[19].

- On 26 January, China instituted measures to contain the COVID-19 outbreak which included extending the Spring Festival holiday to contain the outbreak. Universities and schools around the country decided to close.[20]

- On 23 February, Ministry of Health in Iran announced the closure of educational institute including schools in several cities.[21]

On 3 March, first global numbers on school closures and affected students has been released by UNESCO.

It reported that 13 countries had enacted preventive measures including the temporary closure of schools and universities, impacting 290.5 million students around the world.[22]

On 4 March, As Italy reached 100 deaths, full closure of all schools and universities nationwide[23] ordered by the Italian government. In doing so, Italy became one of 22 countries on three continents which had implemented school closures nationwide.[23]

On 5 March, the majority of learners affected by COVID-19 emergency measures were located in China, with 233 million learners affected, followed by Japan at 16.5 million and Iran at 14.5 million.[24]

By 10 March, one in five students worldwide was "staying away from school due to the COVID-19 crisis" while another one in four was barred from higher education institutions.[25]

- On 13 March, governments in 49 countries announced or implemented school closures, including 39 countries which closed schools nationwide and 22 countries with localized school closures.[26]

- $\quad$ By 16 March, this figure increased from 49 to 73 countries according to UNESCO.[26]

- $\quad$ By 20 March, over $70 \%$ of the world's learners were impacted by closures, with 124 country-wide school closures.[26] 


\section{Consequences of closures of educational institutes worldwide due to pandemic}

Government has decided closures of educational institutes in response to the COVID-19 pandemic, affect the education system as well as broader socio-economic issues. Till 12 March 2020, more than 370 million students in school and colleges are not attending classes because of temporary or indefinite closures of educational institutes declared and implemented by governments worldwide in an attempt to control the spread of COVID-19. As of 20 March, over $70 \%$ of the world's learners were impacted by closures[26]. Over the past 25 days, the number of students affected due to the closures of school and university in 138 countries has nearly quadrupled to 1.37 billion, representing more than 3 out of 4 students worldwide as a result to control Corona spread. In addition, nearly 60.2 million teachers are no longer in the classroom, and using alternative methods of teaching.

Educational institute have high social and economy impact on countries growth. Closures are temporary but carry high social and economic costs. The disruptions they cause affect people across communities, but their impact is more severe for disadvantaged children and their families Including interrupted learning, compromised nutrition, childcare problems and consequent economic cost to families who cannot work [26],[27]. Most of the parents are working now days. For working parents are more likely to manage kids as well as their official work since most of the Companies, offices has not declared shutdown for their employees at that time.

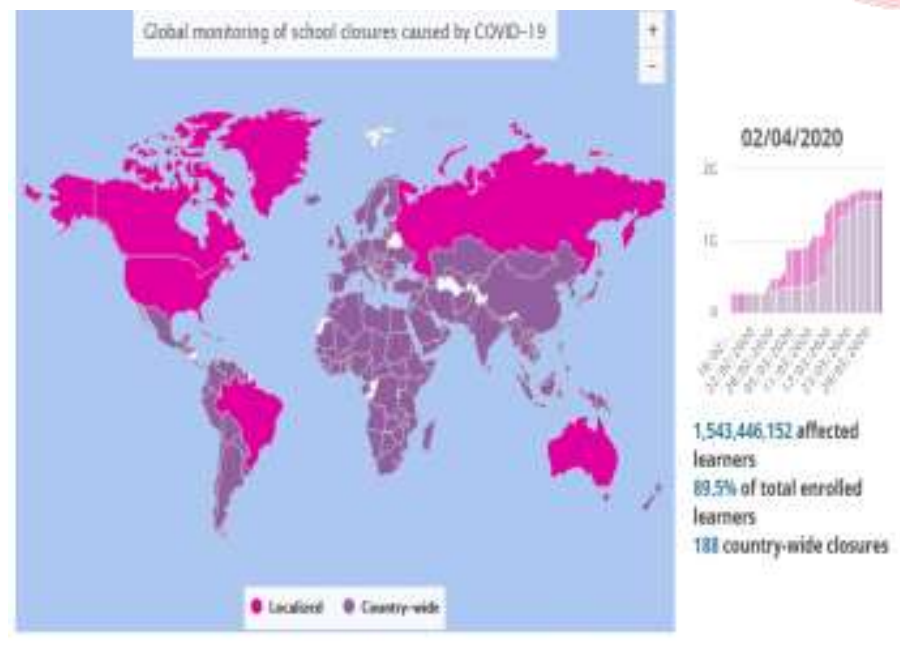

Figure 1 Number of learners enrolled at pre-primary, primary, lower-secondary, and upper-secondary levels of education [ISCED levels 0 to 3], as well as at tertiary education levels [ISCED levels 5 to 8]. Enrolment figures based on latest UNESCO Institute for Statistics data.

\section{Distance learning}

Now days, in educational institutes a hug crowd of students is coming from rural areas. In rural areas, due to the lack of access to technology or fast, reliable internet access can prevent students to access ICT and other online study material. Lack of access to technology or good internet connectivity is an obstacle to continued learning, especially for students from disadvantaged families [28]. Due to the school closures caused by pandemic like COVID19, UNESCO, WHO and UGC recommends the use of distance learning programs and open educational applications and platforms that schools and teachers can use to reach students remotely and limit the disruption of education.

\section{Student learning outcomes}

Educational institute closures due to pandemic, negatively impact student learning outcomes. Education institutes provide essential learning theoretically and practically. But when institutes are closed, students are deprived opportunities for growth and development personally and professionally. The disadvantages are disproportionate for under-privileged students who tend to have fewer educational opportunities beyond school.[29]

Drop-out rates of students tend to increase as a result of institute closures due to the challenge of ensuring all students return to college and school once lockdown ends.

Educational institutes are centers of social activity and human interaction. When lock down is imposed due to pandemic, many children and youth miss out of on social contact that is essential to learning and mental development.

\section{Problem for trainers}

Teachers turn to platforms like Zoom, Google meet, hangout etc. These are disrupting curricula, particularly for teachers less equipped to access the internet and the environment of handling a classroom by a screen and microphone. There are professors cancel their classes because they faced technical problems, difficulties with $\mathrm{WiFi}$ and internet connection, or were panicked and uncomfortable with the idea of taking the full class over the new platform like Zoom or Google meet.

\section{With Respect to the Subject}

Various subjects are taught in educational institutes at various levels. However, the reality is that some subjects are much difficult to teach online. A theoretical subject is easier to teach virtually than a technical and problematic subject. The explanation of the concept based on technical or problematic issues requires chalk and board method of teaching or face to face discussion. Whereas, there are many benefits for teachers and students like classes can be taken anywhere, lack of commute offers more time for studying or external commitments, and the structure is more 
welcoming to students with physical disability or illness. And yet, online learning hasn't threatened the traditional model of in-person learning.

\section{Impact on local economies}

Colleges and Schools operate as an organization which generates significant revenue for cities, states, and countries. For example, Princeton University contributed $\$ 1.58$ billion USD to the New Jersey economy and students spent about $\$ 60$ million in off-campus spending[30]. College and university closures have a negative effect on economic and social growth with farreaching implications.

According to Linda Bilmes of the Harvard Kennedy School, "local hotels, restaurants, cafes, shops, car rental agencies and other local businesses obtain a significant share of annual revenue from graduation week and college reunions, these communities will suffer a lot of economic damage if the colleges remain closed at that time[30]

The local economy and employees to local businesses and companies in small towns are rely on college students to support are especially impacted by school closures and lock down. In Ithaca, New York, Cornell University students spent at least \$4 million a week in Tompkins country. In the wake of Cornell's decision to keep students at home and nation-wide lockdown have horrific economic impact as a result of Cornell University closing [31].

\section{CONCLuSION}

A Chinese proverb stays that 'Opportunity is always present amid crisis'. Danger and opportunity are the two elements that every crisis carries. Always there will be a good opportunity exists, no matter how difficult and dangerous the situation and environment. Each crisis brings a lot of negativity with a tremendous opportunity. In all the fields including education also scope for improvement is there. Today when whole world is fighting against pandemic COVID-19, everyone have the responsibility to protect their country, society and surrounding by facilitating, planning and preparedness efforts. During outbreaks like pandemic, government will impose multiple interventions which make it difficult to assess the effects of educational institutes' closures alone. There are substantial and important negative effects of pandemic like COVID-19 on education. Data from the 2009 pandemic concludes that the closures of educational institutes can reduce transmission of influenza in contemporary settings; however, the outcomes of these students may not be applicable to the pandemic virus like COVID-19 which may have different epidemiological properties and higher mortality rate. We as teachers, during this pandemic, should try an adaptation of the types of education required by the digital age. Whereas special setups and additional trainings required for teachers and students, to conduct effective online teaching and learning during lockdown.
Reactive statewide closures and pro-active national closures both appear to have had an effect on transmission. However, further work is required to assess the relative benefits of different school closure strategies.

\section{REFERENCES}

[1] "COVID-19 Educational Disruption and Response". UNESCO. 2020-03-04. Retrieved 2020-03-23.

[2] "Naming the coronavirus disease (COVID-19) and the virus that causes it". World Health Organization (WHO). Archived from the original on 28 February 2020. Retrieved 28 February 2020.

[3] Hui, D. S.; I. Azhar E.; Madani, T. A.; Ntoumi, F.; Kock, R.; Dar, O.; Ippolito, G.; Mchugh, T. D.; Memish, Z. A.; Drosten, Christian; Zumla, A.; Petersen, E. (February 2020). "The continuing 2019$\mathrm{nCoV}$ epidemic threat of novel coronaviruses to global health-The latest 2019 novel coronavirus outbreak in Wuhan, China". Int J Infect Dis. 91: 264-66. doi:10.1016/j.ijid.2020.01.009. PMID 31953166.

[4] "WHO Director-General's opening remarks at the media briefing on COVID-19". World Health Organization (WHO) (Press release). 11 March 2020. Retrieved 12 March2020.

[5] Q\&A on coronaviruses (COVID-19)". World Health Organization (WHO). Retrieved 11 March 2020.

[6] "Coronavirus Disease 2019 (COVID-19) Symptoms". Centers for Disease Control and Prevention. United States. 10 February 2020. Archived from the original on 30 January 2020.

[7] "Q\&A on coronaviruses". World Health Organization (WHO). Archived from the original on 20 January 2020. Retrieved 27 January 2020.

[8] Simon, Mallory. "Children's coronavirus cases are not as severe, but that doesn't make them less serious". CNN. Retrieved 2020-03-15.

[9] Jump up to:abcBarnum, Matt (2020-03-09). "Should schools close due to coronavirus? Here's what research says". Chalkbeat. Retrieved 2020-03-15.

[10] Frieden, Dr Tom. "Lessons from Ebola: The secret of successful epidemic response". CNN. Retrieved 2020-03-15.

[11] Jackson, Charlotte; Vynnycky, Emilia; Hawker, Jeremy; Olowokure, Babatunde; Mangtani, Punam (2013). "School closures and influenza: systematic review of epidemiological studies". BMJ Open. 3 (2): e002149. doi:10.1136/bmjopen-2012002149. ISSN 2044-6055. PMC 3586057. PMID 23447463.

[12] Markel, Howard; Lipman, Harvey B.; Navarro, J. Alexander; Sloan, Alexandra; Michalsen, Joseph R.; Stern, Alexandra Minna; Cetron, Martin S. (2007-08-08). "Nonpharmaceutical Interventions Implemented by US Cities During the 1918-1919 Influenza Pandemic". JAMA. 298 (6): 654. doi:10.1001/jama.298.6.644. ISSN 00987484. PMID 17684187.

[13] Chin TD, Foley JF, Doto IL, Gravelle CR, Weston J (1960). "Morbidity and mortality characteristics of Asian strain influenza". Public Health Reports. 75 (2): 14858. doi:10.2307/4590751. JSTOR 4590751. PMC 1929395. PMID 1 9316351

[14] Wheeler CC, Erhart LM, Jehn ML (2010). "Effect of school closure on the incidence of influenza among school -age children in Arizona". Public Health Reports. 125 (6): 851859. doi:10.1177/003335491012500612. PMC 2966666. PMID 2112 1230.

[15] Kawano, Shoko; Kakehashi, Masayuki (2015-12-15). "Substantial Impact of School Closure on the Transmission Dynamics during the 
Pandemic Flu H1N1-2009 in Oita, Japan". PLOS One. 10 (12): e0144839. Bibcode:2015PLoSO..1044839K.

[16] Davis, Brian M.; Markel, Howard; Navarro, Alex; Wells, Eden; Monto, Arnold S.; Aiello, Allison E. (2015-06-15). "The Effect of Reactive School Closure on Community Influenza-Like Illness Counts in the State of Michigan During the 2009 H1N1 Pandemic". Clinical Infectious Diseases. 60 (12): e90e97. doi:10.1093/cid/civ182. ISSN 1058-4838. PMID 25896795.

[17] Wardrop, Murray (21 July 2009). "Swine flu: schools should close to halt spread of virus, ministers told". The Telegraph. ISSN 03071235. Retrieved 17 March 2020.

[18] Walsh, Eric, ed. (20 July 2009). "Closing schools won't stop pandemics: study". Reuters. Retrieved 17 March 2020.

[19] https://www.who.int/emergencies/diseases/novel-coronavirus2019/events-as-they-happen

[20] "China's State Council extends Spring Festival holiday Chinadaily.com.cn". chinadaily.com.cn. Retrieved 2020-03-15.

[21] Jump up to:ab"Iran Announces Closure Of Universities, Schools As Coronavirus Death Toll Rises". RFE/RL. Retrieved 2020-03-15.

[22] "290 million students out of school due to COVID-19: UNESCO releases first global numbers and mobilizes response". web.archive.org. 2020-03-12. Retrieved 2020-03-16.

[23] Palermo, Angela Giuffrida Lorenzo Tondo in; Beaumont, Peter (2020-03-04). "Italy orders closure of all schools and universities due to coronavirus". The Guardian. ISSN 0261-3077. Retrieved 2020-0315.

[24] "Coronavirus update: 290 million students now stuck at home". UN News. 2020-03-05. Retrieved 2020-03-15.

[25] "With one in five learners kept out of school, UNESCO mobilizes education ministers to face the COVID-19 crisis". web.archive.org. 2020-03-12. Retrieved 2020-03-16.

[26] "COVID-19 Educational Disruption and Response". UNESCO. Retrieved 2020-03-17.

[27] Inc R. "Coronavirus deprives nearly 300 million students of their schooling: UNESCO | The Telegram". thetelegram.com. Retrieved 11 March 2020.

[28] "Adverse consequences of school closures". UNESCO. 2020-03-10. Retrieved 2020-03-15.

[29] UNESCO (4 March 2020). "290 million students out of school due to COVID-19: UNESCO releases first global numbers and mobilizes response". UNESCO. Retrieved 6 March 2020.

[30] "College Towns to Clear Out as Virus Upends Local Businesses". Bloomberg.com. 2020-03-10. Retrieved 2020-03-22.

[31] Platsky, Jeff. "Loss of Cornell students during coronavirus pandemic could cost Ithaca, Tompkins $\$ 4 \mathrm{M}$ a week". Ithaca Journal. Retrieved 2020-03-22. 